\title{
ANALISA TATA KELOLA TEKNOLOGI INFORMASI UNTUK MENINGKATKAN DESTINASI PARIWISATA DI LOMBOK (STUDI KASUS DI DINAS PARIWISATA PROV. NTB) MENGGUNAKAN FRAMEWORK COBIT 5
}

\author{
(Analysis of Information Technology Governance for Improving Tourism Destination In \\ Lombok (Case Study on Tourism Department of Prov. NTB) Using COBIT 5 Framework)
}

\author{
Septiana Rohman*, Nadiyasari Agitha, Royana Afwani \\ Program Studi Teknik Informatika, Fakultas Teknik, Universitas Mataram \\ Jl. Majapahit 62, Mataram, Lombok NTB, INDONESIA \\ Email:rohman_septiana@yahoo.com, [nadiya,royana]@unram.ac.id
}

\begin{abstract}
IT governance in a company to achieve the company's vision, mission, goals, and objectives. There are problems in IT management both media and website in the Tourism Destination Development Sector, therefore this study determines the Capability level of IT governance in the Tourism Destination Development Sector using the COBIT 5 framework. The framework focuses on the APOO1 sub-domain (Manage the IT management framework) Manage IT management frameworks, and APOO4 (Manage innovation) Develop technological innovation. The results of the Capability level at APOO1 for the current conditions are at levels 2 and 3, while the results of the Capability level at APOO4 for now are at level 2. While the Capability level results at APOO1 and APOO4 for the expected conditions are at levels 4 and 5 To increase the value of the Capability level got, recommendations for improvement are taken into consideration in the Development of Tourism Destinations in managing information technology. Then the recommendations given to increase the Capability level, form an action plan that is equipped with an implementation schedule and an estimated time that can be run.
\end{abstract}

Keywords: IT Governance, COBIT 5, Capability Level, APO01,APO04

*Penulis Korespondensi

\section{Pendahuluan}

Teknologi informasi (TI) saat ini termasuk dalam kebutuhan utama bagi sebuah instansi atau organisasi karena dapat meningkatkan performansi dan efisiensi proses bisnis dari organisasi tersebut. Diketahui juga bahwa Sumber Daya Manusia (SDM) adalah bagian utama untuk keberhasilan kegiatan operasional di instansi dalam rangka mewujudkan visi, misi, tujuan dan sasarannya. Diketahui juga bahwa harus dimilikinya sistem pengolahan SDM yang sesuai dan menyeluruh sesuai dengan kebutuhan perencanaan dan pengembangan instansi tersebut[1].

Dinas Pariwisata adalah badan di bidang kepariwisataan yang didirikan oleh pemerintah sebagai salah satu badan yang diberi kewenangan dalam pengembangan dan pembinaan kepariwisataan baik tingkat nasional maupun tingkat daerah. Dinas Pariwisata Prov. NTB memiliki tanggung jawab tersebut di daerah NTB yang diketahui merupakan salah satu destinasi wisata di Indonesia. Diketahui berdasarkan observasi bahwa penggunaan teknologi pada Bidang Pengembangan Destinasi Pariwisata di NTB yaitu dengan menggunakan media sosial berupa Facebook, Twitters, Instagram, dan website seperti http://www.pesonalomboksumbawa.info dan http:// www.disbudpar.ntbprov.go.id. Sedangkan dalam penyebaran informasinya Bidang Pengembangan Destinasi Pariwisata dibantu oleh Genpi (Generasi Pesona Indonesia). Penggunaan teknologi pada Genpi yaitu dengan menggunakan media sosial dan sistem informasi berupa website seperti http:// www.genpisumbawalombok.com.

Pada proses pengelolaan IT baik media sosial maupun website masih memiliki kendala yang dihadapi, diantaranya kurangnya SDM seperti belum adanya bagian khusus yang memegang kendali atas Tata Kelola Teknologi Informasi (TKTI), serta kurangnya SDM dalam bidang IT apabila terjadi kendala dalam menangani perubahan atau gangguan pada sistem 
yang terjadi secara tiba-tiba. Selain itu juga terdapat kendala pada sumber daya keuangan/anggaran. Kendalakendala tersebut dapat menjadi penghambat pada Bidang Pengembangan Destinasi Pariwisata untuk mencapai tujuannya.

Tata kelola teknologi informasi menggabungkan best practice dari perencanaan dan pengorganisasian $\mathrm{TI} \quad$ pembangunan\&pengimplemen-tasian, delivery\&support, serta memantau kinerja TI untuk memastikan informasi perusahaan atau instansi dan teknologi informasi berhubungan dengan tujuan perusahaan atau instansi [2][3][4]. Dengan Tata Kelola IT diharapkan dapat mengatasi permasalahan SDM dan sumber daya keuangan/anggaran diatas. COBIT 5 (Control Objectives for Information an Related Technology) dibentuk dari pengembangan COBIT 4.1 dengan mengintegrasikan Value IT dan Risk IT dari ISACA, ITIL, dan standar-standar yang relevan berdasarkan ISO. COBIT 5 dapat mendukung sebuah instansi atau organisasi dalam menciptakan nilai yang optimal dari TI dengan menjaga keseimbangan antara kesadaran akan manfaat dan optimalisasi tingkat risiko dan penggunaan sumber daya [5][6].

Berdasarkan permasalahan pada Bidang Pengembangan Destinasi Pariwisata seperti permasalahan sumber daya manusia untuk pengelolaan IT, keuangan dan tata kelola yang masih kurang, maka pada penelitian ini dibuat tata kelola TI pada Bidang Pengembangan Destinasi Pariwisata sesuai dengan visi, misi, tujuan dan sasaran Bidang Pengembangan Destinasi Pariwisata dengan menggunakan framework COBIT 5.

\section{Tinjauan Pustaka}

Pada penelitian ini mengunakan tiga tinjauan pustaka yaitu pertama, penelitian yang berjudul "Perancangan TKTI Di PT Inti Menggunakan Framework Cobit 5 Pada Domain Align, Plan, And Organize (APO)" yang dilakukan oleh I ketut Adi Putra Pranata, Murahartawaty, and Soni Fajar S. Gumilang. Penelitian tersebut Domain APO07 dan APO08 [7].

Penelitian Kedua yaitu penelitian yang berjudul “Analisis TKTI Untuk Meningkatkan Mutu Sumber Daya Manusia Pada Dinas Tenaga Kerja Dan Transmigrasi Provinsi NTB Menggunakan Framework COBIT 5" yang dilakukan oleh Azmi Yunda Chairani. Penelitian ini menggunakan Domain APO01 dan APO07 [8].

Penelitian Ketiga yaitu penelitian yang berjudul “Analisis TKTI Untuk Mendefinisikan Proses TI Pada STIE 45 Mataram Dengan Menggunakan Framework COBIT 4.1" yang dilakukan oleh Nabhan Rabbani. Penelitian ini menggunakan Domain PO4 dan AI7 [9].

\section{Metode Penelitian}

Pada bagian ini akan digambarkan tahapan alur penelitian dengan menggunakan diagram seperti pada Gambar 1.

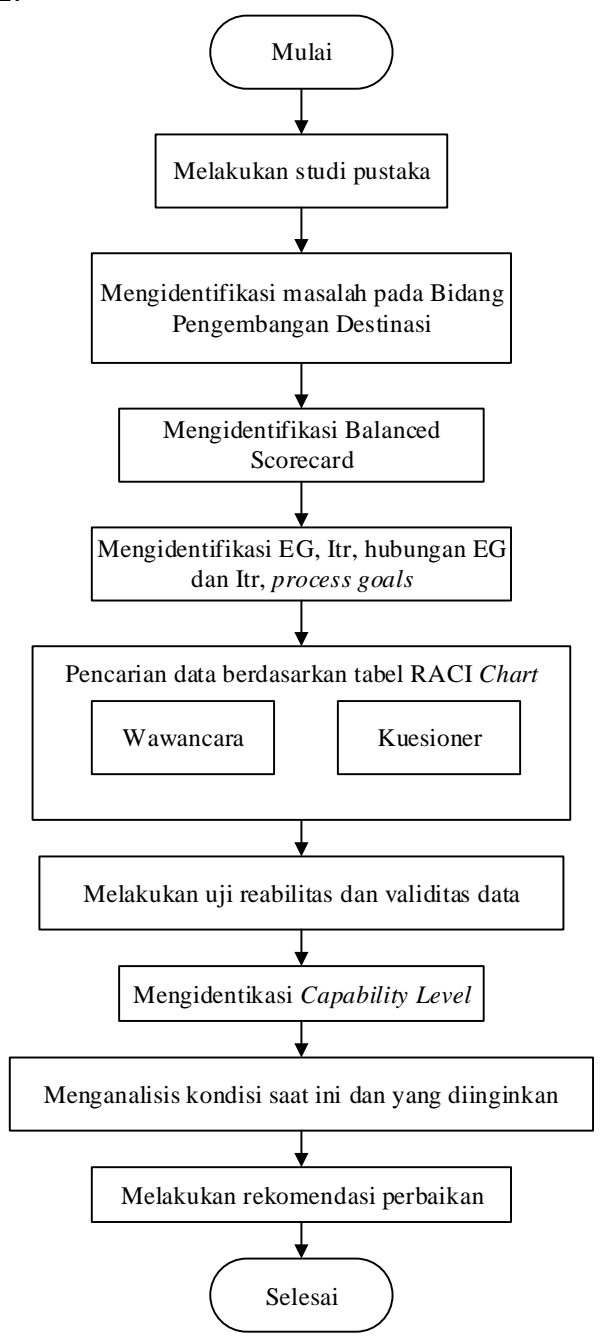

Gambar 1. Flowchart tahapan penelitian

Berdasarkan gambar 1 dapat dijelaskan secara singkat tahapan-tahapan yang dilakukan untuk menyelesaikan penelitian ini sebagai berikut :

1. Pertama dilakukan studi pustaka untuk mencari referensi penelitian sejenis, dan dilakukan pengumpulan data yang berguna bagi penelitian

2. Tahap kedua dilakukan identifikasi masalah dengan cara observasi dan wawancara kepada stakeholder yang terkait dengan TKTI pada Dinas Pariwisata Prov. NTB.

3. Dllakukan identifikasi terhadap visi, misi, tujuan dan sasaran Bidang Pengembangan Destinasi Pariwisata. Dalam pemetaan tersebut, visi, misi, tujuan dan sasaran Bidang Pengembangan Destinasi Pariwisata akan dikelompokan ke dalam 
empat perspektif yang dimiliki oleh Balanced Scorecard (BSC) yaitu sebagai berikut : Financial, Customer, Internal, dan Learning and growth.

4. Pada tahapan in dibagi menjadi 4 sub tahapan yaitu : (a) Pendefinisian Enterprise Goals sesuai dengan COBIT 5.0 yang diselaraskan dengan tujuan bisnis dan sasaran Bidang Pengembangan Destinasi Pariwisata. Dalam COBIT 5, setiap Enterprise Goals (ada 17 Enterprise Goals) sudah dipetakan sesuai dengan 4 perspektif didalam Balanced Scoredcard yaitu: Financial,Customer, Internal, dan Learn \& Growth. Sehingga peneliti dapat memilih Enterprise Goals yang sesuai dengan kebutuhan Bidang Pengembangan Destinasi Pariwisata. (b) Setelah itu dilakukan mapping untuk menentukan IT - Related Goals yang disesuaikan dari enterprise goals yang telah didefinisikan dan selaras dengan visi, misi, tujuan dan sasaran Bidang Pengembangan Destinasi Pariwisata, dimana IT - Related Goals tersebut dapat dijadikan acuan bagi Bidang Pengembangan Destinasi Pariwisata dalam menerjemahkan kebutuhan bisnis akan ketersedian informasi. (c) Kemudian dilakukan mapping untuk menentukan hubungan antara Entreprise Goals (EG) dan IT Related Goals (ITr) . Kemudian menghasilkan dua keterkaitan yaitu primary (P) dimana artinya keterkaitan antara keduanya kuat, dan secondary (S) dimana artinya keterkaitan antara keduanya lemah. (d) Terakhir dilakukan Identifikasi Process goals dengan cara mapping untuk menentukan Process goals yang diambil (ditulis) pada pemetaan yaitu yang memiliki nilai Primary (P) terhadap IT - Related Goals, sedangkan nilai secondary bisa tidak diambil (ditulis) dalam pemetaan karena sebagai nilai pendukung dari keterkaitan antara keduanya, sehingga didapat process goals yang ditulis paling banyak yaitu APO01 dan APO04.

5. Pengumpulan data dilakukan dengan cara wawancara dan quisioner yang diberikan berdasarkan hasil RACl Chart dari process goals yang sudah didapatkan yaitu APO01 dan APO04.

6. Mengidentifikasi Capability Level terhadap process goals yang telah terpilih. Pengukuran capability level ini digunakan untuk mengatur dan mengontrol process goals. Pada model kapabilitas proses dilakukan pengukuran performansi di tiaptiap proses tata kelola atau proses manajemen dimana dilakukan identifikasi dan analisis yang perlu untuk ditingkatkan performansinya [10].

7. Dari hasil sebelumnya, maka selanjutnya dilakukan analisis keadaan saat ini dan keadaan yang akan datang sesuai dengan keadaan pada Bidang Pengembangan Destinasi Pariwisata berdasarkan hasil wawancara dan kuesioner sebelumnya.

8. Setelah menghitung nilai capability level dari hasil kuesioner dan wawancara yang telah dilakukan sebelumnya sehingga ditemukan kesenjangan antara kedua keadaan yaitu keadaan saat ini dan keadaan diharapkan pada kedua process goals yang terpilih yaitu APO01 dan APO04.

9. Dari hasil pengukuran capability level sebelumnya, akan dibuat rekomendasi perbaikan untuk meningkatkan level yang diinginkan.

10. Membuat rencana aksi yang diproyeksikan dapat terlaksana dalam waktu 5 tahun. Rencana aksi dibuat berdasarkan panduan pada COBIT 5 dan disesuaikan dengan keadaan Bidang Pengembangan Destinasi Pariwisata yang sesungguhnya.

11. Membuat Validasi Tata Kelola dengan melakukan pembuktian elemen tata kelola yang diperoleh dari pendapat para ahli tentang tata kelola dan berdasarkan visi dan misi Bidang Pengembangan Destinasi Pariwisata.Tujuan dilakukan validasi tata kelola ini untuk memperkuat dan mengukur sejauh mana kesesuaian hasil yang diperoleh dengan tujuan dan sasaran Bidang Pengembangan Destinasi Pariwisata.

\section{HASIL DAN PEMBAHASAN}

Membahas hasil penelitian yang dilakukan pada Bidang Pengembangan Destinasi Pariwisata yaitu berupa analisis data yang diperoleh selama penelitian dilakukan.

\subsection{Hasil Perhitungan Kuesioner}

Setelah diselesaikan pengisian kuesioner oleh responden yang ditentukan berdasarkan $\mathrm{RACl}$ Roles kemudian diperoleh hasil berupa dua process goals yang terpilih yaitu APO01 (Mengelola kerangka kerja 
manajemen TI) dan APO04 (Mengembangkan inovasi teknologi). Responden pada APO01 sebanyak 35 orang dan responden APO04 sebanyak 24 orang.

\subsubsection{Hasil Perhitungan Nilai IQR}

Boxplot dibuat sebagai representasi dari kedua keadaan yaitu keadaan saat ini dan keadaan yang diharapkan berdasarkan kotak dalam bentuk diagram yang dapat dilihat pada Gambar 2 serta Gambar 3.

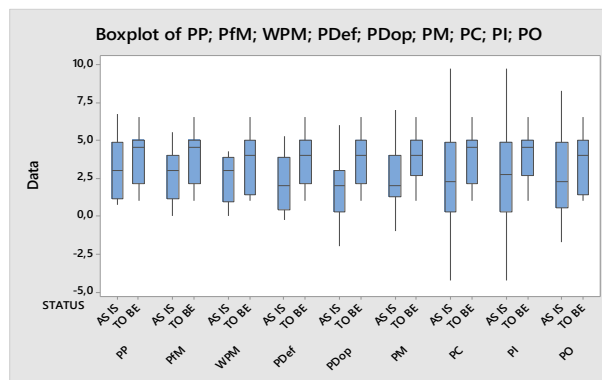

Gambar 2. Diagram boxplot APO01

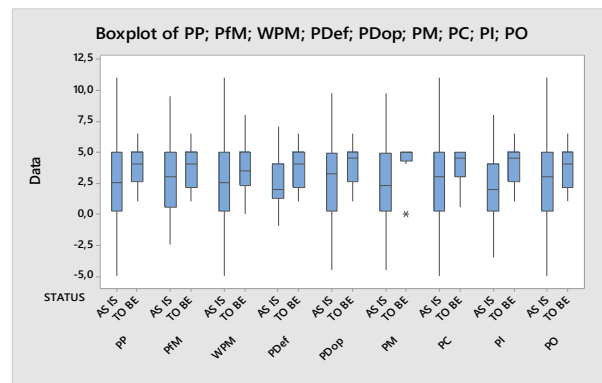

Gambar 3. Diagram boxplot APO04

\subsection{Uji Realiabilitas Dan Validasi Data}

Pada bagian ini akan dijabarkan hasil uji reliabilitas dan validitas data yang didapatkan selama proses penelitian ini

\subsubsection{Uji Realiabilitas Data}

Hasil dari kedua process goals yaitu APO01 dan APO04 menggunakan Cronbach's Alpha yang dapat dilihat pada Tabel I.

Tabel I. Nilai reliabilitas APO01 dan APO04

\begin{tabular}{|c|c|c|c|c|}
\hline NO & $\begin{array}{c}\text { Process } \\
\text { Goals }\end{array}$ & Status & Alpha & Reliabilitas \\
\hline \multirow{2}{*}{1} & \multirow{2}{*}{ APO01 } & Saat ini & 0.8048 & Reliabilitas \\
\hline & & Diharapkan & 0.7876 & Reliabilitas \\
\hline \multirow{2}{*}{2} & \multirow{2}{*}{ APO04 } & Saat ini & 0.9154 & $\begin{array}{l}\text { Sangat } \\
\text { Reliabilitas }\end{array}$ \\
\hline & & Diharapkan & 0.9096 & $\begin{array}{l}\text { Sangat } \\
\text { Reliabilitas }\end{array}$ \\
\hline
\end{tabular}

\subsubsection{Uji Validasi Data}

Hasil dari kedua process goals yaitu APO01 dan APO04 menggunakan Korelasi Pearson atau Product Moment yang dapat dilihat pada Tabel II dan Tabel III.

Tabel II. Nilai validitas APO01

\begin{tabular}{|c|c|c|c|c|c|}
\hline NO & $\begin{array}{l}\text { Atri- } \\
\text { but }\end{array}$ & Status & $\begin{array}{c}r- \\
\text { Hitung }\end{array}$ & $\begin{array}{c}\mathrm{r}- \\
\text { Tabel } \\
(\mathrm{N}=35)\end{array}$ & $\begin{array}{l}\text { Vali- } \\
\text { ditas }\end{array}$ \\
\hline \multirow[t]{2}{*}{1} & \multirow{2}{*}{ PP } & Saat ini & 0,722 & 0.334 & $\begin{array}{c}\text { Valid } \\
\text { (V) }\end{array}$ \\
\hline & & Diharapkan & 0,658 & 0.334 & V \\
\hline \multirow{2}{*}{2} & \multirow{2}{*}{ PfM } & Saat ini & 0,693 & 0.334 & V \\
\hline & & Diharapkan & 0,682 & 0.334 & $\mathrm{~V}$ \\
\hline \multirow{2}{*}{3} & \multirow[b]{2}{*}{ WPM } & Saat ini & 0,682 & 0.334 & V \\
\hline & & Diharapkan & 0,722 & 0.334 & $\mathrm{~V}$ \\
\hline \multirow{2}{*}{4} & \multirow{2}{*}{ PDef } & Saat ini & 0,412 & 0.334 & V \\
\hline & & Diharapkan & 0,405 & 0.334 & $\mathrm{~V}$ \\
\hline \multirow{2}{*}{5} & \multirow{2}{*}{ PDop } & Saat ini & 0,636 & 0.334 & $\mathrm{~V}$ \\
\hline & & Diharapkan & 0,633 & 0.334 & $\mathrm{~V}$ \\
\hline \multirow{2}{*}{6} & \multirow{2}{*}{ PM } & Saat ini & 0.638 & 0.334 & V \\
\hline & & Diharapkan & 0,630 & 0.334 & $\mathrm{~V}$ \\
\hline \multirow{2}{*}{7} & \multirow{2}{*}{ PC } & Saat ini & 0,519 & 0.334 & V \\
\hline & & Diharapkan & 0,468 & 0.334 & $\mathrm{~V}$ \\
\hline \multirow{2}{*}{8} & \multirow{2}{*}{$\mathrm{PI}$} & Saat ini & 0,693 & 0.334 & $\mathrm{~V}$ \\
\hline & & Diharapkan & 0,661 & 0.334 & $\mathrm{~V}$ \\
\hline \multirow{2}{*}{9} & \multirow{2}{*}{$\mathrm{PO}$} & Saat ini & 0,667 & 0.334 & $\mathrm{~V}$ \\
\hline & & Diharapkan & 0,689 & 0.334 & V \\
\hline
\end{tabular}

Tabel III. Nilai validitas APO04

\begin{tabular}{|c|c|c|c|c|c|}
\hline $\begin{array}{c}\mathrm{N} \\
\mathrm{O}\end{array}$ & $\begin{array}{c}\text { Atri- } \\
\text { but }\end{array}$ & Status & $\begin{array}{c}\mathrm{r}- \\
\text { Hitu- } \\
\mathrm{ng}\end{array}$ & $\begin{array}{c}\mathrm{r} \text {-Tabel } \\
(\mathrm{N}=24)\end{array}$ & $\begin{array}{c}\text { Vali- } \\
\text { ditas }\end{array}$ \\
\hline \multirow{2}{*}{1} & \multirow{2}{*}{ PP } & Saat ini & 0,907 & 0.404 & $\begin{array}{c}\text { Valid } \\
\text { (V) }\end{array}$ \\
\cline { 3 - 6 } & & Diharapkan & 0,876 & 0.404 & $\mathrm{~V}$ \\
\hline \multirow{2}{*}{2} & \multirow{2}{*}{ PfM } & Saat ini & 0,790 & 0.404 & $\mathrm{~V}$ \\
\cline { 3 - 6 } & Diharapkan & 0,686 & 0.404 & $\mathrm{~V}$ \\
\hline \multirow{2}{*}{3} & \multirow{2}{*}{ WPM } & Saat ini & 0,771 & 0.404 & $\mathrm{~V}$ \\
\hline & & Diharapkan & 0,754 & 0.404 & $\mathrm{~V}$ \\
\hline \multirow{2}{*}{4} & \multirow{2}{*}{ PDef } & Saat ini & 0,792 & 0.404 & $\mathrm{~V}$ \\
\hline & & Diharapkan & 0,761 & 0.404 & $\mathrm{~V}$ \\
\hline \multirow{2}{*}{5} & \multirow{2}{*}{ PDop } & Saat ini & 0,499 & 0.404 & $\mathrm{~V}$ \\
\hline & & Diharapkan & 0,559 & 0.404 & $\mathrm{~V}$ \\
\hline \multirow{2}{*}{6} & \multirow{2}{*}{ PM } & Saat ini & 0,730 & 0.404 & $\mathrm{~V}$ \\
\hline & Diharapkan & 0,785 & 0.404 & $\mathrm{~V}$ \\
\hline \multirow{2}{*}{7} & \multirow{2}{*}{ PC } & Saat ini & 0,799 & 0.404 & $\mathrm{~V}$ \\
\cline { 3 - 6 } & Diharapkan & 0,721 & 0.404 & $\mathrm{~V}$ \\
\hline
\end{tabular}




\begin{tabular}{|c|c|c|c|c|c|}
\hline $\begin{array}{c}\mathrm{N} \\
\mathrm{O}\end{array}$ & $\begin{array}{c}\text { Atri- } \\
\text { but }\end{array}$ & Status & $\begin{array}{c}\mathrm{r}- \\
\text { Hitu- } \\
\mathrm{ng}\end{array}$ & $\begin{array}{c}\mathrm{r}-\text { Tabel } \\
(\mathrm{N}=24)\end{array}$ & $\begin{array}{c}\text { Vali- } \\
\text { ditas }\end{array}$ \\
\hline \multirow{2}{*}{8} & \multirow{2}{*}{$\mathrm{PI}$} & Saat ini & 0,873 & 0.404 & $\mathrm{~V}$ \\
\cline { 3 - 6 } & Diharapkan & 0,514 & 0.404 & $\mathrm{~V}$ \\
\hline \multirow{2}{*}{9} & \multirow{2}{*}{$\mathrm{PO}$} & Saat ini & 0,860 & 0.404 & $\mathrm{~V}$ \\
\cline { 2 - 6 } & Diharapkan & 0,863 & 0.404 & $\mathrm{~V}$ \\
\hline
\end{tabular}

\subsection{Mengidentifikasi Capability Level}

Nilai capability level pada kedua process goals dapat dicari dengan menggunakan persamaan (1).

\section{$\mathbf{X}=\Sigma$ (level jawaban * jumlah responden) Jumlah keseluruhan responden}

Setelah dilakukan seluruh perhitungan nilai capability level pada setiap atribut untuk keadaan saat ini dan keadaan yang diharapkan pada APO01 dan APO04, kemudian dilakukan konversi kedalam tabel, seperti pada Tabel IV. dan Tabel V.

Tabel IV. Capability level APO01

\begin{tabular}{|c|c|c|c|c|c|}
\hline \multirow{2}{*}{ NO } & \multirow{2}{*}{$\begin{array}{c}\text { ATRI- } \\
\text { BUT }\end{array}$} & \multicolumn{2}{|c|}{ Nilai Kematangan } & \multicolumn{2}{c|}{$\begin{array}{c}\text { Tingkat } \\
\text { kematangan }\end{array}$} \\
\cline { 3 - 6 } & & $\begin{array}{c}\text { Saat } \\
\text { ini }\end{array}$ & Diharapkan & $\begin{array}{c}\text { Saat } \\
\text { ini }\end{array}$ & $\begin{array}{c}\text { Diha- } \\
\text { rapkan }\end{array}$ \\
\hline 1 & PP & 3.057 & 4.4 & 3 & 4 \\
\hline 2 & PfM & 3 & 4.485 & 3 & 4 \\
\hline 3 & WPM & 2.714 & 4.171 & 3 & 4 \\
\hline 4 & PDef & 2.2 & 4.142 & 2 & 4 \\
\hline 5 & PDop & 1.857 & 3.971 & 2 & 4 \\
\hline 6 & PM & 2.4 & 4.085 & 2 & 4 \\
\hline 7 & PC & 1.8 & 4.342 & 2 & 4 \\
\hline 8 & PI & 2.085 & 4.485 & 2 & 4 \\
\hline 9 & PO & 1.942 & 3.885 & 2 & 4 \\
\hline $\begin{array}{r}\text { RATA - } \\
\text { RATA }\end{array}$ & 2.339 & 4.218 & 2 & 4 \\
\hline
\end{tabular}

Tabel V. Capability level APO04

\begin{tabular}{|c|c|c|c|c|c|}
\hline \multirow{2}{*}{$\begin{array}{c}\text { N } \\
\text { O }\end{array}$} & \multirow{2}{*}{$\begin{array}{c}\text { ATRI } \\
\text {-BUT }\end{array}$} & \multicolumn{2}{|c|}{ Nilai Kematangan } & \multicolumn{2}{c|}{$\begin{array}{c}\text { Tingkat } \\
\text { kematangan }\end{array}$} \\
\cline { 3 - 6 } & & $\begin{array}{c}\text { Saat } \\
\text { ini }\end{array}$ & $\begin{array}{c}\text { Diha- } \\
\text { rapkan }\end{array}$ & $\begin{array}{c}\text { Saat } \\
\text { ini }\end{array}$ & $\begin{array}{c}\text { Diha- } \\
\text { rapkan }\end{array}$ \\
\hline 1 & PP & 2.167 & 4.25 & 2 & 4 \\
\hline 2 & PfM & 1.75 & 3.958 & 2 & 4 \\
\hline 3 & $\begin{array}{c}\text { WP } \\
\text { M }\end{array}$ & 2.291 & 3.708 & 2 & 4 \\
\hline 4 & PDef & 1.875 & 3.708 & 2 & 4 \\
\hline 5 & $\begin{array}{c}\text { PDo } \\
\text { p }\end{array}$ & 2.417 & 4.458 & 2 & 4 \\
\hline
\end{tabular}


predictable, kecuali pada atribut PA 4.1 dan PA 4.2 yang ada di tingkat 5 yaitu optimizing.

\subsection{Analisa Keadaan Saat Ini Dan Diharapkan}

Pada bagian ini akan dijabarkan sebagian Analisa yang dilakukan untuk mendapatkan penjelasan tentang kondisi saat ini dan kondisi yang diharapkan

\subsubsection{Analisa Keadaan Saat Ini}

Berdasarkan tingkat kematangan keadaan saat ini pada Tabel II, berikut sebagian analisa keadaan saat ini yang dapat dijelaskan :

1. Pada APO01 atribut PA 1.1 (proses kinerja) ada di tingkat 3 dimana artinya bahwa proses kinerja pada Bidang Pengembangan Destinasi Pariwisata yang didukung oleh sarana dan prasarana dalam meningkatkan kerangka kerja manajemen TI agar sesuai dengan tujuan dari Bidang Pengembangan Destinasi Pariwisata. Sedangkan APO04 berada padalevel 2 dimana artinya bahwa proses kinerja terkait pengembangkan inovasi teknologi yang dilakukan oleh Bidang Pengembangan Destinasi Pariwisata telah diimplementasikan sesuai dengan tujuan Bidang Pengembangan Destinasi Pariwisata seperti pengembangan website.

2. Pada APO01 atribut PA 2.1 (manajemen kinerja) ada di tingkat 3 dimana artinya bahwa manajemen kinerja yang terdapat pada Bidang Pengembangan Destinasi Pariwisata dalam mengelola kerangka kerja manajemen $\mathrm{TI}$, untuk memiliki kompetensi dan professional kerja dalam mengembangkan layanan publik seperti membagikan informasi melalui website Dinas Pariwisata NTB. Sedangkan APO04 ada di tingkat 2 dimana artinya bahwa manajemen kinerja yang dilakukan oleh Bidang Pengembangan Destinasi Pariwisata dalam mengembangkan inovasi teknologi dalam meningkatkan kinerja dan pengembangan kemampuan staff memaksimalkan pelayanan program pengenalan sistem infomasi teknologi informasi kepada masyarakat dalam penyebaran tetang destinasi dijalankan sesuai dengan tanggung jawab untuk menjalankan proses-proses yang telah disepakati.

3. Pada APO01 atribut PA 2.2 (manajemen hasil kinerja) ada di tingkat 3 dimana artinya bahwa hasil kinerja yang telah mencapai target untuk mengelola kerangka kerja manajemen $\mathrm{TI}$ didokumentasikan dan dikontrol yaitu mendokumentasi dalam bentuk laporan atau buku tahunan seperti buku rencana strategi setiap tahun pasti berubah. Sedangkan APO04 ada di tingkat 2 dimana artinya yaitu Bidang Pengembangan Destinasi Pariwisata sudah memiliki manajemen hasil kerja seperti melakukan identifikasi masalah dalam penggunaan dan pemeliharaan infrastruktur TI.

4. Pada APO01 dan APO04 atribut PA 3.1 (proses definisi) ada di tingkat 2 dimana berarti pendefinisian standar dan kebijakan yang terdapat pada Bidang Pengembangan Destinasi Pariwisata untuk mengelola kerangka kerja manajemen $\mathrm{TI}$ dan mengembangkan inovasi teknologi sudah dijalankan SOP yang jelas seperti tetapi belum optimal.

\subsubsection{Analisa Keadaan Diharapkan}

Berdasarkan tingkat kematangan kindisi Diharapkan pada Tabel II, berikut beberapa Analisa keadaan diharapkan yang dapat dijelaskan :

1. Pada APO01 atribut PA 1.1 (proses kinerja) ada di tingkat 5 dimana artinya pada Bidang Pengembangan Destinasi Pariwisata menginginkan adanya kinerja proses yang dioptimalkan dengan dukungan sarana dan prasarana yang ditingkatkan untuk memenuhi kerangka kerja manajemen TI. Sedangkan APO04 ada di tingkat 4 dimana artinya Bidang Pengembangan Destinasi Pariwisata menginginkan proses kinerja yang diperoleh dari pengumpulan data kinerja dan pengelolaan kinerja dalam mengembangankan inovasi teknologi dapat dioperasikan sesuai dengan tujuan dari Bidang Pengembangan Destinasi Pariwisata dan dapat diimplementasikan dengan baik.

2. Pada APO01 dan APO04 atribut PA 2.1 (manajemen kinerja) ada di tingkat 4 dimana artinya yaitu Bidang Pengembangan Destinasi Pariwisata menginginkan adanya kinerja manajemen sudah ada memiliki kompetensi dan profesionalisme dalam pengembangan layanan publik.

3. Pada APO01 dan APO04 atribut PA 2.2 (manajemen hasil kinerja) ada di tingkat 4 dimana artinya yaitu manajemen hasil kinerja pada Bidang Pengembangan Destinasi Pariwisata menginginkan target yang dicapai untuk mengelola kerangka kerja manajemen TI diimplementasikan dan dioperasikan sesuai kebutuhan Dinas Pariwisata sebagai instansi terkait.

4. Pada APO01 dan APO04 atribut PA 3.1 (proses definisi) ada di tingkat 4 dimana artinya yaitu proses pendefinisian mengenai kebijakan dan 
standar pada Bidang Pengembangan Destinasi Pariwisata menginginkan adanya assesment terhadap peraturan serta standar untuk infrastruktur dan lingkungan kerja dalam melakukan pengelolaan kerangka kerja manajemen $\mathrm{TI}$.

\subsection{Rekomendasi Perbaikan}

Pada bagian ini dibuat rekomendasi perbaikan yang dapat dilakukan oleh organisasi atau dalam hal ini adalah Dinas Pariwisata Prov. NTB untuk mencapai level kondisi yang diinginkan

\subsubsection{Rekomendasi Tindakan Atau Aktivitas Untuk Mencapai Level 3 Pada APO01}

Tabel VI Tindakan atau aktivitas yang dilakukan untuk perbaikan agar mencapai capability level 3 pada APO01.

Tabel VI. Rekomendasi PA 3.1

\begin{tabular}{|c|l|}
\hline Atribut & Aktivitas untuk perbaikan \\
\hline & $-\quad \begin{array}{l}\text { Mendefinisikan kebijakan dan } \\
\text { standar serta panduan yang }\end{array}$ \\
PA 3.1 & digunakan untuk melakukan \\
(process & proses mengelola kerangka \\
definition) & kerja manajemen TI agar \\
& dapat berjalan secara baik. \\
\hline
\end{tabular}

Pada Table VI. Rekomendasi untuk mencapai level 3 pada APO01 yaitu proses pengelolaan kerangka kerja manajemen IT harus diimplementasi dengan baik dan teratur sesuai dengan tujuan dari Bidang Pengembangan Destinasi Pariwsata.

\subsubsection{Mencapai Level 4 Pada APO01}

Tabel VII. Tindakan atau aktivitas yang dilakukan untuk mencapai capability level 4 pada APO01

\begin{tabular}{|c|c|}
\hline Atribut & Aktivitas perbaikan \\
\hline $\begin{array}{c}\text { PA } 1.1 \\
\text { (process } \\
\text { performance) }\end{array}$ & 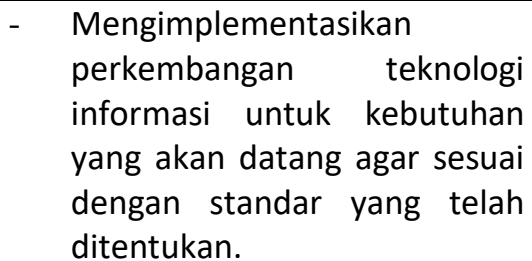 \\
\hline
\end{tabular}

Pada Table VI. Rekomendasi untuk mencapai level 4 pada APO01 yaitu proses sudah berjalan dan dioperasikan sesuai kebutuhan yang akan datang agar sesuai dengan tujuan dari Bidang Pengembangan Destinasi Pariwsata.

\subsubsection{Rekomendasi Tindakan Untuk Mencapai Level 3 Pada APO04}

Tabel VIII. Tindakan atau aktivitas yang dilakukan untuk mencapai capability level 3 pada APO04

\begin{tabular}{|c|lr|}
\hline Atribut & \multicolumn{3}{|c|}{ Aktivitas perbaikan } \\
\hline & - Merencanakan & proses \\
PA 1.1 & \multicolumn{2}{|c|}{ pembuatan aplikasi yang } \\
(process & digunakan oleh & Bidang \\
performance) & Pengembangan & Destinasi \\
& Pariwisata. & \\
\hline
\end{tabular}

Pada Table VIII. Rekomendasi untuk mencapai level 3 pada APO04 yaitu pengembangan aplikasi diimplementasi dengan baik agar sesuai dengan tujuan dari Bidang Pengembangan Destinasi Pariwsata.

\subsubsection{Rekomendasi Tindakan Untuk Mencapai Level 4 Pada APO04}

Tabel IX. Tindakan atau aktivitas yang dilakukan untuk mencapai capability level 4 pada APO04

\begin{tabular}{|c|c|c|}
\hline Atribut & \multicolumn{2}{|c|}{ Aktivitas perbaikan } \\
\hline $\begin{array}{c}\text { PA } 1.1 \\
\text { (process } \\
\text { performance) }\end{array}$ & $\begin{array}{l}\text { - Melakukan } \\
\text { teknologi } \\
\text { tujuan. }\end{array}$ & $\begin{array}{l}\text { pengembangan } \\
\text { sesuai dengan }\end{array}$ \\
\hline
\end{tabular}

Pada Table VI. Rekomendasi untuk mencapai level 4 pada APO04 yaitu proses pengembangan teknologi berjalan sesuai dengan tujuan dari Bidang Pengembangan Destinasi Pariwsata.

\subsubsection{Rekomendasi Tindakan Untuk Mencapai Level 5 Pada APO04}

Tabel $\mathrm{X}$. Tindakan atau aktivitas yang dilakukan untuk mencapai capability level 5 pada APO04

\begin{tabular}{|c|c|}
\hline Atribut & Aktivitas perbaikan \\
\hline $\begin{array}{c}\text { PA } 4.1 \\
\text { (process } \\
\text { measurement) }\end{array}$ & $\begin{array}{l}\text { - Melakukan pengawasan dan } \\
\text { pengukuran untuk mendapat } \\
\text { tujuan yang dicapai. }\end{array}$ \\
\hline
\end{tabular}

Pada Table VI. Rekomendasi untuk mencapai level 5 pada APO04 yaitu perusahaan melakukan pengawasan dan pengukuran agar sesuai dengan tujuan dari Bidang Pengembangan Destinasi Pariwsata.

\subsection{Rencana Aksi}

Tabel XI. Rencana Aksi

\begin{tabular}{|c|c|c|c|c|c|c|c|c|c|c|}
\hline \multirow{3}{*}{$\begin{array}{l}\mathrm{N} \\
\mathrm{O}\end{array}$} & \multirow{3}{*}{ Aksi } & \multirow{2}{*}{\multicolumn{2}{|c|}{$\begin{array}{l}20 \\
19\end{array}$}} & \multirow{2}{*}{\multicolumn{2}{|c|}{$\begin{array}{l}20 \\
20\end{array}$}} & \multirow{2}{*}{\multicolumn{2}{|c|}{$\begin{array}{l}20 \\
21\end{array}$}} & \multirow{2}{*}{$\begin{array}{l}20 \\
22\end{array}$} & \multirow{2}{*}{\multicolumn{2}{|c|}{$\begin{array}{l}20 \\
23\end{array}$}} \\
\hline & & & & & & & & & & \\
\hline & & I & I & I & I & I & I & I & & 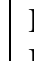 \\
\hline
\end{tabular}




\begin{tabular}{|c|c|}
\hline 1 & $\begin{array}{l}\text { Membuat } \\
\text { renstra dalam } \\
\text { pengambilan } \\
\text { keputusan } \\
\end{array}$ \\
\hline & $\begin{array}{l}\text { a. melakukan } \\
\text { pengembangan } \\
\text { IT Pariwisata }\end{array}$ \\
\hline & $\begin{array}{l}\text { b.Meningkatkan } \\
\text { kualitas SDM } \\
\text { pariwisata dan } \\
\text { kesiapan } \\
\text { masyarakat }\end{array}$ \\
\hline & $\begin{array}{l}\text { c.Meningkatkan } \\
\text { kualitas } \\
\text { pemasaran } \\
\text { pariwisata }\end{array}$ \\
\hline 2 & $\begin{array}{l}\text { Membuat } \\
\text { indikator kinerja } \\
\text { utama untuk } \\
\text { mengukur } \\
\text { kinerja SD } \\
\text { dalam } \\
\text { pencapaian } \\
\text { tujuan }\end{array}$ \\
\hline & $\begin{array}{l}\text { a.melakukan } \\
\text { pengoptimalan, } \\
\text { peningkatan, } \\
\text { dan pemulihan } \\
\text { destinasi } \\
\text { pariwisata }\end{array}$ \\
\hline & $\begin{array}{l}\text { b.menigkatkan } \\
\text { jumlah } \\
\text { kunjungan } \\
\text { wisatawan }\end{array}$ \\
\hline & $\begin{array}{l}\text { c.Melakukan } \\
\text { pengomptimala } \\
\mathrm{n} \text { dan } \\
\text { pemulihan } \\
\text { sektor ekonomi }\end{array}$ \\
\hline & $\begin{array}{l}\text { d.Meningkat } \\
\text { kinerjapemasar } \\
\text { an destinasi }\end{array}$ \\
\hline 3 & $\begin{array}{l}\text { Menetapkan } \\
\text { struktur } \\
\text { organisasi staf } \\
\text { IT }\end{array}$ \\
\hline 4 & $\begin{array}{l}\text { Melakukan } \\
\text { koordinasi } \\
\text { dengan seluruh } \\
\text { staf untuk } \\
\text { menentukan } \\
\text { tugas dan } \\
\text { tanggung jawab } \\
\text { masing- masing } \\
\text { staf IT }\end{array}$ \\
\hline
\end{tabular}

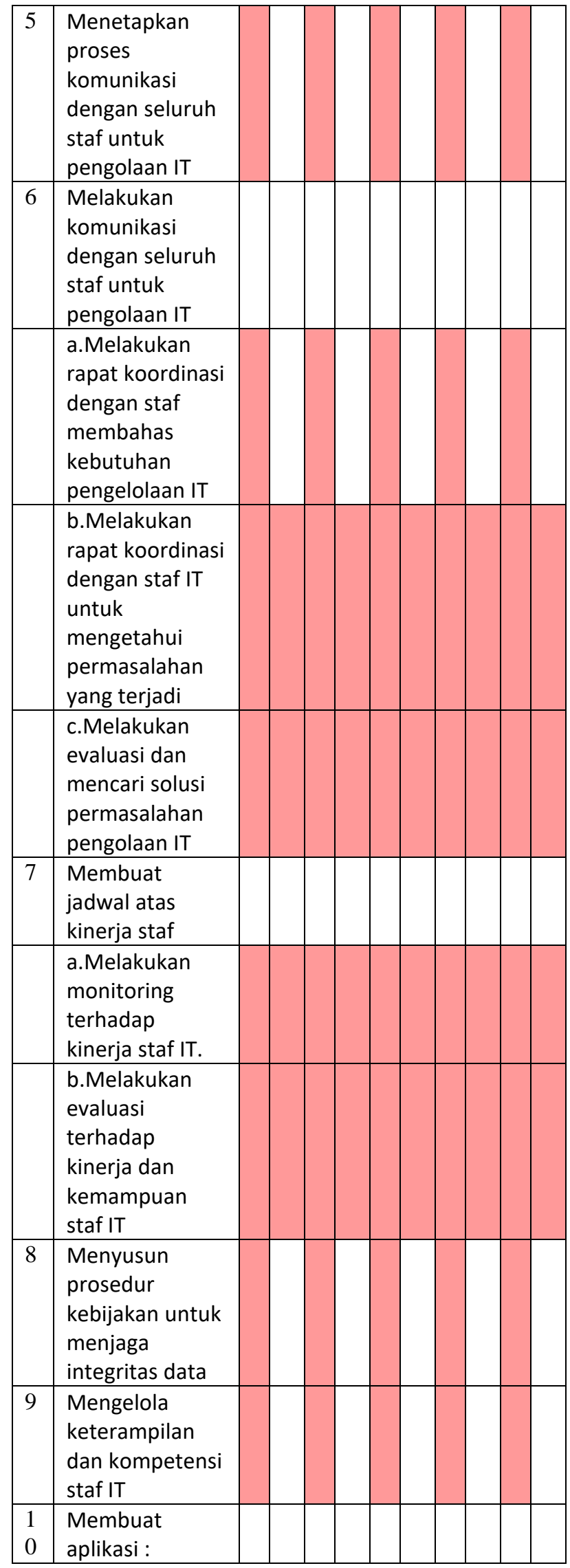




\begin{tabular}{|c|c|}
\hline & $\begin{array}{l}\text { a. Melakukan } \\
\text { rapat } \\
\text { koordinasi } \\
\text { membahas } \\
\text { pembuatan } \\
\text { sistem } \\
\text { apilkasi } \\
\text { wisata NTB } \\
\text { \& sistem } \\
\text { pendukung } \\
\text { keputusan } \\
\text { destinasi }\end{array}$ \\
\hline & $\begin{array}{l}\text { b.melakukan } \\
\text { rapat anggaran } \\
\text { dana untuk } \\
\text { pembuatan } \\
\text { apilkasi. }\end{array}$ \\
\hline & $\begin{array}{l}\text { c.membuat } \\
\text { sistem apilkasi } \\
\text { wisata NTB \& } \\
\text { sistem } \\
\text { pendukung } \\
\text { keputusan } \\
\text { destinasi }\end{array}$ \\
\hline & $\begin{array}{l}\text { d.melakukan } \\
\text { lauching aplikasi }\end{array}$ \\
\hline & $\begin{array}{l}\text { e.melakukan } \\
\text { sosialisai } \\
\text { aplikasi }\end{array}$ \\
\hline $\begin{array}{l}1 \\
1\end{array}$ & $\begin{array}{l}\text { Melakukan } \\
\text { evalusi } \\
\text { kerhasilan } \\
\text { kinerja staf IT } \\
\text { terhadap } \\
\text { penerapan IT } \\
\text { sesuai SD yang } \\
\text { diterapakan }\end{array}$ \\
\hline
\end{tabular}

\section{KESIMPULAN DAN SARAN}

\subsection{Kesimpulan}

Berdasarkan hasil penelitian Analisa Tata Kelola Teknologi Informasi Untuk Meningkatkan Destinasi Pariwisata Di Lombok, didapatkan kesimpulan sebagai berikut:

1. Setiap process goals yang terpilih memiliki capability level yang berbeda - beda, dimana level untuk keadaan saat ini ada di tingkat 1,2, dan 3, sedangkan untuk keadaan akan datang menginginkan ada di tingkat 4 dan 5 .

2. Hasil capability level untuk keadaan saat ini pada APO01 ada di tingkat 2, dimana artinya Pada tahap ini sudah terdapat inisiatif untuk melakukan pengelolaan kerangka kerja menejemen IT namun belum ada SOP untuk menjalan proses tersebut dan level 3 dimana artinya proses yang dijalankan sudah sesuai dengan tujuan dari Bidang Pengembangan Destinasi Pariwisata.

3. Hasil capability level untuk keadaan saat ini pada APO04 berada pada level 2. Hal ini berarti Pada tahap ini sudah terdapat inisiatif pengoptimalan inovasi teknologi akan tetapi belum konsisten dan belum dilakukan secara formal.

4. Hasil capability level untuk keadaan diharapkan pada APO01 dan APO04 ada di tingkat 4 dan 5 hal ini berarti manajemen pada Bidang Pengembangan Destinasi Pariwisata NTB akan menetapkan beberapa indikator untuk mengukur kinerja proses dan terdapat prosedur yang tetap untuk mengelola kerangka kerja manajemen TI dan mengembangkan inovasi teknologi.

5. Rekomendasi dibuat untuk mengelola, memantau, dan mengevaluasi hasil kinerja staf $\mathrm{TI}$ dan perkembangan inovasi teknologi. Pengelolaan teknologi informasi secara bertahap yang dimulai dari nilai capability level keadaan saat ini sampai keadaan yang diinginkan.

6. Rencana aksi yang diusulkan sudah dikonsultasikan dan disesuaikan dengan kebutuhan Bidang Pengembangan Destinasi Pariwisata dan telah mendapat persejutuan serta memungkinkan untuk dapat digunakan dalam kebijakan pengelolaan teknologi informasi di Bidang Pengembangan Destinasi Pariwisata

\subsection{Saran}

Saran yang dapat diberikan berdasarkan hasil penelitian ini yaitu agar hasil tata kelola dapat lebih maksimal, instansi diharapkan dapat memadukan hasil penelitian serupa pada process goals yang lain, sehingga pada pelaksanaannya dapat lebih terintegrasi dan mendapatkan hasil yang maksimal.

\section{DAFTAR PUSTAKa}

[1] I. R. Alit. M. Idhom, "Analisis Sumber Daya Manusia Teknologi Informasi Menggunakan Kerangka Kerja COBIT 4.1 (Studi Kasus: Unit Pelaksana Teknik Telematika Universitas Pembangunanan Nasional "Veteran" Jawa Timur)," KINETIK, vol. I, no. 2, pp. 101-106, 2016.

[2] IT Governance Institute, Framework Control Objectives Management Guidelines Maturity Models, 2007.

[3] K. Surendro, Implementasi Tata Kelola Tekologi Informasi, Bandung: informatika, 2009. 
[4] M. Afifuddin, "Perancangan Tata Kelola Teknologi Informasi Menggunakan Framework Cobit $5 \mathrm{Di} \mathrm{Pt}$ Sier," pp. 1-7, 2015.

[5] I. P. A. Swastika and I. G. L. A. R. Putra, "Audit Sistem Informasi dan Tata Kelola Teknolgi Informasi," Andi, Yogyakarta, 2016.

[6] ISACA, A Business Framework for the Governance and Management of Enterprice IT, USA: ISACA, 2012

[7] I. ketut A. P. Pranata, Murahartawaty, and S. F. S. Gumilang, "Perancangan Tata Kelola Teknologi Informasi Di Pt. Industri Telekomunikasi Indonesia (Inti) Menggunakan Framework Cobit 5 Pada Domain Align, Plan, And Organize (APO)," e-Proceeding of Engineering, vol. II, no. 2, p. 5830, 2015.

[8] A. Y. Chairani. R. Afwani. S. Endang, Laporan Analisis Tata Kelola Teknologi Informasi Untuk Meningkatkan
Mutu Sumber Daya Manusia Pada Dinas Tenaga Kerja Dan Transmigrasi Provinsi Nusa Tenggara Barat Menggunakan Framework COBIT 5, Mataram: Program Studi Teknik Informatika Fakultas Teknik Universitas Mataram, 2019.

[9] N. Rabbani. N. Agitha. S. Endang, "Analisis Tata Kelola Teknologi Informasi Untuk Mendefinisikan Proses TI Pada STIE 45 Mataram Dengan Menggunakan Framework COBIT 4.1," JTIKA, vol. I, no. 1, pp. 1-12, 2019.

[10] F. Muhafiizh, Suprapto, and R. I. Rokhmawati, "Evaluasi Sumber Daya Manusia Teknologi Informasi Perusahaan Menggunakan COBIT 5 ( Studi Kasus : PT Krakatau Steel (Persero) Tbk)," J.Pengemb. Tekno. Inf. dan IImu Komput., vol. I, no. 12, pp. 1687-1696, 2010. 